\title{
Critical contrastive rhetoric in action: Iranian EFL learners' writing in focus
}

Rafiee, Marzieh $\bowtie$

University of Isfahan, Iran (rafieemarzieh@gmail.com)

Vahid Dastjerdi, Hossein

University of Isfahan, Iran (h_vahid@yahoo.com)

Tavakoli, Mansor

University of Isfahan, Iran (mr.tavakoli14@gmail.com)

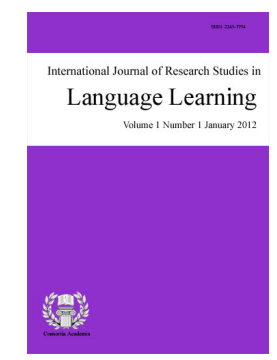

ISSN: 2243-7754 Online ISSN: 2243-7762

OPEN ACCESS

\section{Abstract}

Since its appearance in the domain of critical pedagogy, critical contrastive rhetoric has been used as an approach to critically investigate the cultural and linguistic differences involved in structuring texts. Based on the assumptions behind poststructuralist, postcolonial, and postmodern critiques of language and culture, this study attempts to examine new and additive ways of writing in a group of EFL learners by raising her critical awareness of rhetorical organization of their mother tongue and the target language. To this end, data were triangulated from different sources: in-depth daily observations, audio-tapes of interviews, classroom discussion and reflective questionnaire. The results indicated that through the dialogical and problem-posing processes, students became more reflective on the differences between the complex web of rhetoric in their L1 and L2.

Keywords: critical contrastive rhetoric; contrastive rhetoric; cultural difference; written discourse; action research 


\section{Critical contrastive rhetoric in action: Iranian EFL learners' writing in focus}

\section{Introduction}

Since its appearance in the domain of text and genre analysis, contrastive rhetoric has been used as an approach to investigate the cultural and linguistic factors involved in the structuring of texts. Usually the desire to translate first language rhetorical patterns while writing in the second language leads second language writers to frustration through the process of language learning. Furthermore, as Subrahmanian (1975) states, one major hindrance that an ESL/EFL writer must tiptoe through is the awareness of existing cultural differences between two languages. The term contrastive rhetoric, originally introduced by Kaplan (1966), was the first attempt to examine the role of these differences, to investigate the difficulties ESL/EFL students experience and to measure the influence of L1 cultural and linguistic transfer during L2 writing (Connor, 1996).

Traditional contrastive rhetoric turned its attention to the assumption proposed by Sapir-Whorf, i.e. there is a link between culture and thought. In this regard, contrasting and comparison of the rhetorical organization of different genres in different languages that may interfere in the process of writing by non-native students constitutes the lion's share of the traditional contrastive rhetoric research. The pressing issue that needs to be addressed here is the political and ideological images existing in the network of rhetorical patterns of various written languages, the issue which was on the top agenda in the heyday of classical contrastive rhetoric.

The major concern of critical contrastive rhetoric is to unravel the political and social transformations of "cultural differences" explored in the traditional contrastive rhetoric (Kubota \& Lehner, 2004). This new trend is served as a starting point for connecting contrastive rhetoric to a "broader political concern" which views rhetorical organization, in the narrow sense, and language learning and teaching, in the broader sense, as "political concerns" (Pennycook, 2001, p. 10).

Drawing on this theoretical framework the present study attempts to fill the existing gap in complete understanding of the critical process of text construction in L2 writing. The study also thrives to increase critical awareness for students of the thresholds in rhetorical organization of writing English. What follows is a brief summary of theoretical backgrounds for critical contrastive rhetoric.

\section{Theoretical backgrounds}

\subsection{Contrastive Rhetoric}

The basic premise of classical contrastive rhetoric, according to Kaplan (1966) was the study of the influence of linguistic and cultural differences of rhetorical patterns of L1 in the process of writing L2. The studies done in the domain of contrastive rhetoric emphasize the interference of rhetorical conventions of students' L1 with her EFL/ESL writing; the hypothesis that links contrastive rhetoric to the structuralist linguistic and behaviorism (see Connor 1996, 2002, 2003 for overview).

The growing body of research in postmodernism, post-structuralism, post-colonialism leads the researchers to criticize the primary hypothesis in contrastive rhetoric. The picture classical contrastive rhetoric was trying to build up, viewing culture and linguistic background as "discrete, discontinuous, and predictable" (Zamel, 1997, p. 343), has been replaced by a relativistic assumption of contrastive rhetoric which implies that "different language communities represent different cultures and literacy practices" (Canagarajah, 2002, p. 34). In this vantage point, Zamel (1997, p. 345) warns us to avoid the trap of cultural determinism and to explore a "range of factors that may be influencing our students' writing". One of these factors that were thoroughly discussed in critical theory of language learning and critical contrastive rhetoric is writer's performance and understanding. The next section 
summarizes this issue.

\subsection{Critical Contrastive Rhetoric}

Armed with the works produced by the Frankfurt Circle, Critical Theory, which is served as the beginning point for the appearance of Critical Pedagogy and its sub-disciplines, "offered an unrelenting critique of contemporary sources and cause of oppression and repression" (Willinsky, 2007, p. 1). The educational edge of this theory, being emerged in different ways, emphasizes on the "political nature of education" (Wardekker \& Miedema, 1997, p. 46) as its central issue. On the continuum of Critical Theory, Critical Literacy asks readers and writers to approach the text by a critical perspective. In Shor's (1999, p. 4) words, Critical Literacy is a means by which we can question "power relations, discourses, and identities in a world not yet finished, just, or humane" in dealing with text, and community in the general sense.

Thanks to the changing notions of community as a "static, homogeneous" to a "hybrid" and "heterogeneous set of values" (Canagarajah, 2002, p. 31), it is assumed that multilingual students diverse between the values of discourse of one community to the others. Looking through the issue by a critical lens, multilingual studies have recently explored the reasons why a writer from specific community may adopt a specific practice of writing. This would link the academic discourse to the ideological interests and values of students; a notion which is favored by the Critical Literacy (Kaur, 2013). In this vein, there was an effort to rejuvenate the tradition of contrastive rhetoric by studying the issue in a critical perspective. Kubota and Lehner (2004, p. 9) summarizes the aim of Critical Contrastive Rhetoric as follows:

Critical contrastive rhetoric encourages teachers and students to critically reflect on classroom practices such as comparing and contrasting L1 and L2 rhetorical patterns and teaching/learning "preferred" discourse patterns of the target language and to reevaluate how these practices might reinforce cultural binaries and assimilation.

The framework used in this study is based on some theoretical underpinnings adopted from post-structural, post-colonial and post-modernism schools of thought. The following principles, adopted for Kubota and Lehner (2004), of these three schools of thought are considered in the study:

$>$ Cultural differences are perceived to be discursively constructed.

$>\quad$ Discursive construction of knowledge induces politicization of cultural differences.

$>$ Classroom dialogue, which underlines cultural differences in rhetoric, could preserve cultural stereotyping and unequal relations of power.

$>\quad$ Linguistic and cultural relations of power influence language change as well as bilingual writers' identities and her perceptions of L1 and L2 rhetoric.

$>\quad$ Diasporic and hybrid nature of language and rhetoric have an effect on participants' writing performances and views of writing.

Taking previous studies in the field of contrastive rhetoric and critical applied linguistic as a starting point, the present study tries to describe the critical awareness raising and change of perception of a group of EFL learners in their L1/L2 rhetorical organization writing. The following research questions are the focus of attention in this study:

1. What are the impacts of CCR instruction on the process of L2 writing?

2. How does CCR instruction affect the participants' attitude and perceptions?

3. How does explicit instruction of CCR affect the product (increasing the quality of L1/L2 writers) of 
writing?

\section{Methodology}

\subsection{Participants}

The participants in this study consisted of 12 senior students ( 4 male and 8 female students), aged between 21-26, who were enrolling in writing course at a state university in Iran (the sampling was done through purposeful sampling). The emphasis of this course is on preparing students for their postgraduate requirements (e.g. classroom essay writing, course project, article writing, thesis writing, etc.). According to participants response to a bio-data questionnaire (see Appendix A) administered before the study, nine of them had begun studying English in high school and three of them in elementary school. Also more than half of the students, i.e. 7 students were studying English in institutes and had already been taught how to write English essays. The detailed information of participants is presented in Table 1.

\section{Table 1}

Characteristics of Interview Participants

\begin{tabular}{rrllcc}
\hline No & Age & Gender & Academic Status & \multicolumn{2}{c}{$\begin{array}{c}\text { Language Learning } \\
\text { private institutes }\end{array}$} \\
\hline 1 & 21 & female & Senior & 4 & 8 \\
2 & 22 & female & Senior & 4 & 4 \\
3 & 22 & male & Senior & 4 & 0 \\
4 & 22 & female & Senior & 4 & 0 \\
5 & 22 & female & Senior & 4 & 0 \\
6 & 23 & male & Senior & 4 & 5 \\
7 & 23 & female & Senior & 4 & 0 \\
8 & 25 & male & Senior & 4 & 8 \\
9 & 22 & female & Senior & 4 & 0 \\
10 & 26 & female & Senior & 4 & 7 \\
11 & 24 & male & Senior & 4 & 5 \\
12 & 22 & female & Senior & & \\
\hline
\end{tabular}

\subsection{Data collection}

Due to the complex nature of subject matter, the present study assumes action research principles to create a dynamic and comprehensive framework to deal with the issue at hand. In this vein, critical literacy instruction synthesis developed by Janks (2000) was worked out in the data collection procedure. The model asserts that how explicit instructions of the rhetorical conventions of L1 and L2 would increase learners' awareness of the relationship between power and language. The different, yet interdependent, orientations of this model include clear understanding and answer the following questions:

Domination: how does critical awareness of rhetorical conventions work, and is worked out, to serve the interest of the dominant discourse? Who has empowered and disempowered by the language used?

Access: how does making visible the generic features of the dominant discourse to writers give them greater access to those features?

D Diversity: how explicit instructions of the rhetorical patterns of the L1 and L2 change learners' consciousness of the range of modalities in writing? How does awareness of diversity make students feel at ease with sharp L1/L2 differences of cultural aspects?

Design: how does critical literacy increase writers' ability to generate and reconstruct a number of new meanings? 
Furthermore, the study combined Janks' (2000) critical literacy synthesis (domination, access, diversity and design) with Bailey's (1996) model. The first model asserts that how explicit instructions of the rhetorical conventions of L1 and L2 would increase learners' awareness of the dominant discourse, and their access to the dominant discourse and rhetoric. The model also helps participants acquire diversity of literacy and design new meanings. The second focuses more on aspects of classroom process, i.e. increasing learners' critical understanding of the four elements of critical literacy, participants i.e. learner/teachers' attitude, reflection and perceptions of this new approach to learning/teaching rhetorical conventions, and their products, i.e. increasing the quality of participants' L2 writing.

\subsection{Action Research Framework}

Action Research framework was used to empower the present researchers to leverage their professional understanding in order to change participants' perceptions of L1/L2 rhetorical organization and classroom practice. In seeking the effectiveness of change in practice, a triangulation of data-gathering techniques, e.g. in-depth daily observations, audio-tapes of interviews, classroom discussion and reflective questionnaire, was employed to illuminate different aspects of participants' change of perception and product. The study was conducted in the Advanced Writing class (four credit hours, 100 minutes per week) for one semester (4 months).

\section{Data Analysis}

This study applied Burn's (2010) action research steps to be implemented as a classroom research. According to Burn (2010, p. 7), any action research project involves four "spiral of cycles" which iterate until the action researcher has achieved a satisfactory outcome and feels it is time to stop. Below is a summary of the steps followed in this project.

\subsection{Planning}

The first phase of this project aimed to identify the problems Iranian EFL learners face during their graduate and postgraduate life. The goal was to diagnose the shortcomings students suffer from in their L2 writing and develop a plan of action to bring about improvements and enhancement in their ability to have critical understanding of $\mathrm{L} 2$ rhetorical patterns.

During their experience of language teaching, the researchers had encountered students moaning and groaning about their needs and difficulties in L2 writing. The common and customary method in teaching L2 writing in research setting is giving EFL learners yardsticks and principles of writing and then asking them to write different types of writing assignments without receiving enough instruction on the critical dimensions of L2 writing. Language learners are not properly instructed on the observed differences between the organizational patterns in their L1 and L2, let alone for the critical underpinnings of these differences. Thus, the desperate need of language learners to move toward the mainstream in language teaching, i.e. critical understanding of text construction, led the researchers to work out the principles of CCR in order to fill out the gap existing in the educational setting.

\subsection{Action}

In this phase, the researchers had a "deliberate intervention" into their own teaching (Burn, 2010, p. 7), i.e. putting the plans into actions for the purpose of developing a better understanding of the phenomenon. In the current study, the researchers repeatedly questioned their assumptions about the issues of concern and planned new and additive ways to overcome the limitations of traditional methods. Just as the data collection procedures in other research approaches, in this phase the researchers gathered data in order to gain deeper insight and understanding about teaching and learning issues. The following observational and non-observational methods (Burn, 2010) were applied as data collection procedures. 
Classroom Discussion and Observation - In each session of instruction, the researchers brought some introductory, but influential, notes on the principles of critical writing and more specifically on the differences between English and Persian organizational patterns. The notes drew a vivid picture of the participants' L1 and L2 linguistic, rhetorical and cognitive preferences.

The way the notes were organized roughly reflects two levels of analysis as follows:

$>$ Critical linguistics: reading/writing meaning from the text (genre and the organization of text, text and conceptual meaning, text and interpersonal meaning).

$>$ Critical discourse: reading/writing meanings into the text (interpreting discourse, reading and writing positions, inter-textuality)

After explaining the note of each part, students were provided with some contrastive examples chosen from Persian and English writing samples. The examples were discussed in the class and then students were required to do some writing activities in the class or at home. Sometimes, there were one-to-one dialogues and discussion between teacher and the students who run into problems during their writings. The instructors observed and recorded what happened in the class in written notes and collected a reflection log on the process of a change in the understanding of language learners as well.

Participants' Writing Portfolio - A copy of students' writing was collected once a week over the whole semester. The purpose of collecting these portfolios was twofold: identify the main improvement participants had and diagnosing further instructions they need. The essays were submitted via email to the researchers. The writing logs were then analyzed based on the features of CCR presented to participants by teacher's classroom notes. The teacher hand the writing sample back to students in order to let them create a log of their line of progress. In order to have a holistic view of the impact of explicit CCR instruction on participants' writing production, they were required to write two argumentative essays, one in Persian and one in English, both before and after the instruction. The purpose behind the task was to analyze their writing and spot the differences in participants' writing in these two phases of study.

Reflection Interviews - Through purposive sampling, 5 participants were chosen to be interviewed. The students were interviewed on the campus, lasting 30-40 minutes. The interviews then were recorded, transcribed and back-translated for further analysis. The interviews were conducted in participants' L1, Persian, "thus removing concerns about the proficiency of the learner impacting the quality and quantity of the data provided" (Mackey \& Gass, 2005, p. 174). The purpose of interview questions was to elicit participants' perceptions and attitudes toward their writing performance and to see how their views of writing changed to the hybrid nature of language and rhetoric. Four criteria were taken into consideration while choosing the interview participants; the positive and valuable contribution of participants in classroom and homework tasks, passing some courses at private language institutes so they have the experience of L2 writing, attendance in almost all of the course sessions and their willingness in taking part in the interview session. With the aim of providing a holistic view of the major purposes served by CCR instruction, the interview section began with the following questions in mind: the degree to which this course has changed participants views of L2 writing; the extent to which they increase their critical understanding of L2 writing and especially their understanding of CCR; to gain greater insight into the classroom context and the degree to which the context has helped them improve their understanding of discursive nature of language and rhetoric.

Questionnaire - Immediately after the submission of the essays by the participants, they were given a perception questionnaire adopted from Allen (2004), Bateman (2004) and Janks (2000) (see Appendix B). Being composed of five sections, the questionnaire elicits information on the participants' evaluation and feedback on the CCR instruction project, besides their perceptions of similarity/differences between L1 and L2 writing in terms of contrastive rhetoric. 


\subsection{Observation}

The purpose of this phase is to analyze the data gathered in the previous section.

The method of constant comparison described by Glaser and Strauss (1967) was worked out in order to analyze the gathered data. The method contains four stages. First, the data were compared to be applied into the two categories, based on the aforementioned research questions: 1) the impacts of CCR instruction on the process (increasing language learners' understanding of the issues of dominance, access, diversity and design) of L2 writing, 2) the effect CCR instruction had on the participants' attitude and perceptions. In addition, the data were further organized by data type (e.g. transcribed interview, teacher observational notes, etc.). In order to integrate categories and properties, the data were reread many times. Key words were diagnosed for grouping them into groups and subgroups. The third stage was to make a linkage between these codes and produce some patterns. Finally, three themes were produced out of these patterns which are fully described in the final stage of AR.

\subsection{Reflection}

At this point, the researcher reflects on, evaluate and describe the results of actions which have been done in order to make sense of what happened, the results of the actions and to do a further cycle of action, if needed.

The themes emerged out of analyzing the data are as follows:

$>\quad$ The text writing with a different attitude

$>\quad$ Sharp awareness of the synthesis of critical literacy

$>\quad$ Positive perceptions of L1/L2 contrastive rhetoric differences

Writing text with a different attitude - The results of transcribed interview, teacher notes and questionnaire indicate that there was a clear shift in the participants' point of view about the nature of L2 writing. As mentioned by most of them during the interview session, they were accustomed to the traditional style of wiring which, as the starting point, makes EFL learners familiar with the mechanical aspects of L2 writing, such as the location of topic sentence, the identification of main idea, etc. Hardly were they instructed with the other aspects of compositions such as underlying meanings transferred from writer to reader, writers' agency and subjectivities, diasporic and hybrid nature of language and rhetoric, and many others (Kubota \& Lehner, 2004).

In comparing this method of instruction to the other methods, Student 6 said:

This method is more productive than the other methods. Before, we were required to write, we just wrote, without having any special technique of writing. In those methods, we just applied the words, but now, these techniques are more helpful. Now we can recognize the power relationships between the writer and the reader, we also have the ability to recognize the importance of the fact that while we are writing, we should be able to recognize our relations with the reader.

The above example demonstrates that through classroom discussions and individual inquiry, student 6 not only was enthusiasm in new method of writing, but also increases his insight into the critical features of L2 writing.

Of great importance in the analysis of the results was the fact that participants were conscious of the deficiency of methods of teaching writing other than critical ones, and tried to shift their attention from those methods to new ones, the fact clearly reflected in what student 1 commented:

When I was in institute, I usually wrote the way it is called "Shah Abbasi", I mean writing without paying attention to what you are writing. I just made effort to write the way my teacher is 
Rafiee, M., Vahid Dastjerdi, H., \& Tavakoli, M.

teaching. But now, the situation changed! I know I can influence my reader by my choice of words, by the structures I apply, by the codes I put into my writing in order to help my reader decode it.

Student 9 confirms her classmates' comments and complaints about the "mechanical method of teaching" by providing a vivid example:

The way I was instructed in institutes and, also during my English learning, was, let's say, impersonal! We were instructed to write as mechanically as possible. Even we were told to indent the first line of each paragraph. I mean too much emphasis on the mechanical rules of writing, but nothing about its underlying features!

Critical thinking and sharp awareness of the synthesis of CCR - The quantitative and qualitative analysis of the results support the researcher initial assumption that students participating in this project would go under a process of critical thinking in their writing. As the elements of CCR were explained to them in different phases of study and they were required to do some activities based on them, the participants gained insights into the critical literacy components, i.e. domination, access, diversity and design. The results of self-evaluated questionnaire revealed that 60 percent of participants agreed that the course helped them improve their understanding of the elements of CCR. Bringing a convincing example in Persian, Student 7 mentioned that:

Sometimes we say, "I found the solution" in contrast to "the solution came to my mind", you see how different they are?! You can analyze the text from an external source. If you use the second statement, you would not be criticized! You say this is what comes to mind! You investigate the text from an outside source! I mostly applied the passive structure in my writing, thus If anyone is to blame, it is not me! You know, we were instructed to write passive structures in our texts. This method helped me stop to think; I stop and think about the differences!

The technique mentioned by this student is called "passivisation", which is applied in both languages "to protect sources by omitting the sayer, or to retail her own opinions as though they were someone else's (Goatly, 2000, p. 76). Compared with its English counterpart, the Persian writing was recorded to be more reader-responsible in terms of its organizational patterns (Crismore \& Abdollehzadeh, 2011; Pishghadam \& Attaran, 2013). The discursive knowledge of English and Persian of these differences helped this student engage in another way in the act of writing.

Teacher's observational notes written after each session of instruction revealed this change of subjectivities and engagement in L2 writing, moving on a continuum from very dogmatic position to more reflexive one. The following excerpt chosen from teachers' notes clearly indicate the issue:

\section{Reflection note (second session)}

"The need for organization", it was the first session topic of discussion. Students were given some introductory notes on the thematic structure of paragraph. In the class, they were required to do activity 3 (cited in Goatly, 2000). It seems they are really unfamiliar with these things and unwilling to know more about them. While I was observing their performance, one of them told me, "if you want to work on our writing, give us some instruction about the general rules! I think these are out-of-reach in our writing. Let us do some vocabulary and grammar tasks in the class!"

\section{Reflection note (eighth session)}

Today we discussed the issue of "pronoun use" in writing and the differences between Persian and English. When I brought some examples from both samples of writing, mostly students agreed that Iranian students don't use the first person pronoun in writing. When I asked for the 
reason, one of them said "because Iranian students are modest in her writing"!

Positive perceptions of L1/L2 contrastive rhetoric differences - The item analysis in the questionnaire (see table 2) revealed that students gained insight into the differences between their L1 and L2 writing, regarding the cultural differences. The first two items of questionnaire which seeks to inquire participants' view on their understanding of the particular aspects of English/Persian writing, mostly rated high in students' view. 66.6 and 58.3 percent of participants replied that they gained insight into the aspect of their second and first language respectively. Regarding the process of writing in general (item 3), quite a high number of participants (33.3) agreed that the course helped them to be aware of the process of writing, while 41.6 percent strongly agreed that they engaged in critical thinking in writing. The last four items tried to explore the participants' attitude toward the synthesis of critical literacy, i.e. domination, access, diversity and design. Nearly all of the participants rated these items high, indicating they agreed that the course influence their perceptions of these items.

Table 2

Students' Self-evaluation Questionnaire

\begin{tabular}{|c|c|c|c|c|}
\hline \multicolumn{5}{|c|}{ Agreement } \\
\hline 1 & 2 & 3 & 4 & 5 \\
\hline \multicolumn{5}{|c|}{ I gained insight into a particular aspect of English language writing. } \\
\hline $1(8.3)$ & 0 & $1(8.3)$ & $2(16.6)$ & $8(66.6)$ \\
\hline \multicolumn{5}{|c|}{ I gained insight into the same aspect in my own first language writing. } \\
\hline 0 & $1(8.3)$ & $1(8.3)$ & $3(25)$ & $7(58.3)$ \\
\hline \multicolumn{5}{|c|}{ I became more aware of my own process of language writing. } \\
\hline 0 & $1(8.3)$ & $2(16.6)$ & $4(33.3)$ & $5(41.6)$ \\
\hline \multicolumn{5}{|c|}{ I engaged in critical thinking during my writing. } \\
\hline 0 & 0 & $1(8.3)$ & $6(50)$ & $5(41.6)$ \\
\hline \multicolumn{5}{|c|}{ Language is a powerful means of maintaining relations of domination } \\
\hline 0 & 0 & $2(16.6)$ & $8(66.6)$ & 2(16.6) \\
\hline \multicolumn{5}{|c|}{ This course gave me the power to access the dominant forms of language. } \\
\hline 0 & 0 & 0 & $4(33.3)$ & $8(66.6)$ \\
\hline \multicolumn{5}{|c|}{ The course gave me insight into the various types of rhetorical patterns of L1 and L2 } \\
\hline 0 & 0 & 0 & $2(16.6)$ & $10(83.3)$ \\
\hline \multicolumn{5}{|c|}{ This method increased my ability to generate new meanings in my L1/L2 writing. } \\
\hline 0 & $2(16.6)$ & $2(16.6)$ & $5(41.6)$ & $3(25)$ \\
\hline
\end{tabular}

The last two items of questionnaire attempted to measure participants' understanding of the discursive nature of contrastive rhetoric differences in their L1 and L2. Participants were required to write their reasons if they consciously tried to write English and Persian differently. In analyzing the responses, a number of 10 students (83.3 percent) rated their understanding of English/Persian language writing high. In explaining the reasons whether they wrote their essays, both English and Persian, differently in terms of content and/or text organization, most of them mentioned that this course helped them to gain a conscious understanding of the differences between these two languages. One of them wrote:

Although in institute I was used to write English the way I wrote Persian, here I understood that there are some sharp differences between them. Sometimes I put some gaps between the two tasks [writing English and Persian essay] in order to avoid one language impact on the other (students 14, questionnaire analysis).

The other student stated that

I understand the fact that Persian has its own style and organization, so I try to apply its own model for writing!

This fact is clearly reflected in their product, i.e. after-instruction essays. The following section tries to answer the third research question. 
Rafiee, M., Vahid Dastjerdi, H., \& Tavakoli, M.

Analyzing the participants' product - Rhetorical analysis of participants' product was carried out in order to show the similarities/differences between the pre/post essays writing of participants. The model proposed by Kubota (1998) was worked out in order to find the location of main idea and the macro-level rhetorical patterns. This model would clearly show how the writing in L1 and L2 would affect each other and investigates whether CCR instruction would help participants avoid negative transfer of L1 to L2 or vice versa.. According to this model, there are five locations for the main ideas: initial (Init.), middle (Midd.), final (Fin.), collection (Coll.) and obscure (Obsc.) (See Appendix $\mathrm{C}$ for the definition of each location). The other aspect of this framework deals with the analysis of macro-level rhetorical patterns, namely: Collection (Col), Comparison (Comp), Explanation (Exp), Induction following Comparison (Comp Ind), Specification (Spec), and Induction (Ind) (see Appendix D for definitions). Kubota (1998) distinguished between the "inductive" and "deductive" macro-pattern in the essays. There is a correspondence between the location of main idea and the macro-level pattern. According to Kubota (1998), the pattern of essays would be either inductive (final-main-idea position), deductive (initial-main-idea position) or a combination of both. The following table shows the results.

Table 3

Analysis of Main Idea, Patterns, and Structure Unit of Two Sets of Writing

\begin{tabular}{|c|c|c|c|c|c|c|c|c|}
\hline & \multicolumn{4}{|c|}{ Pre-essay writing } & \multicolumn{4}{|c|}{ Post-essay writing } \\
\hline & MI & & Patt. & & MI & & Patt. & \\
\hline & Per. & Eng. & Per. & Eng. & Per. & Eng. & Per. & Eng. \\
\hline S1 & Init. & Init. & Exp & $\operatorname{Exp}(\mathrm{Col})$ & Fin. & Init. & Exp. & Spec(col) \\
\hline $\mathrm{S} 2$ & Init. & Init. & Exp & Exp & Fin. & Init. & Exp. & $\operatorname{Exp}(\mathrm{col})$ \\
\hline S3 & Coll. & Obsc. & $\operatorname{Exp}(\mathrm{Col})$ & Exp. & Midd. & Midd. & Spec. & $\operatorname{Exp}(\mathrm{col})$ \\
\hline S4 & Init. & Init. & Exp. & Spec. & Midd. & Init. & Exp(comp) & Spec. \\
\hline S5 & Init. & Init. & Ind & Exp. & Fin. & Init. & $\operatorname{Ind}(\mathrm{col})$ & Exp. \\
\hline S6 & Init. Coll. & Init. & Exp. & Exp. & Fin. & Init. & $\operatorname{Exp}(\mathrm{col})$ & Exp. \\
\hline S7 & Init. & Init. & Other & Exp. & Fin. & Init. & Exp. & Exp. \\
\hline S8 & Init. & Init. & Spec (Col) & Spec $(\mathrm{Col})$ & Fin. & Init. & Exp. & Exp. \\
\hline S9 & Init. Obsc. & Init. & Exp. & Exp. & Init. & Init. & $\operatorname{Exp}(\mathrm{col})$ & Exp. \\
\hline S10 & Init. & Init. & Exp. & $\operatorname{Exp}(\mathrm{Col})$ & Midd. & Init. & $\operatorname{Exp}(\mathrm{col})$ & Exp. \\
\hline S11 & Init. & Init. & Exp. & Exp. & Midd. & Init. & Exp. & Exp. \\
\hline $\mathrm{S} 12$ & Init. Obsc. & Init. & Exp. & Exp. & Fin. & Init. & $\operatorname{Exp}(\mathrm{col})$ & Exp. \\
\hline
\end{tabular}

These results indicate that the locations of main idea is L1 and L2 pre-instruction essays were similar, showing that participants were unaware of the differences between the rhetorical patterns specific to their L1, and had an attempt to mimic the L2 rhetorical patterns in their L1 writing. Participant 3 was an exception to this case. As the demographic table of participants shows, this writer had only one-year instruction in private institutes, showing his lack of competence and instruction on L2 writing. As regard with the macro-level rhetorical patterns, which has a correlation with the location of main idea (Kubota, 1998), L1/L2 essays belong to the explanation and specification category, showing that there was a transfer of L2 to L1 writing.

Concerning the post-instruction essays, it must be noted that, there was a clear shift in the location of main idea in L1 and L2 essays. Contrary to their pre-instruction essays, which had the same main idea location in the L1 and L2, their post-instruction essay writing were different, indicating that they had the attempt to keep the two languages separate from each other, i.e. critical understanding of the rhetorical patterns of L1 and L2. This point has been reflected in their answer to the last items of questionnaire.

\section{Discussion}

The general aim of this study was to investigate the triple principles of process (increasing the participants' critical understanding of writing process), participants (change of attitude and perception toward writing) and product (increasing the quality of their L2 writing) as mentioned by Baily (1996). By blending Baily's model with the synthesis of critical literacy proposed by Janks (2000) together, the researchers attempted to give a complete and comprehensive picture of Iranian EFL learner' writing. As the results found, instead of writing L2 
texts without being conscious of the boundaries between English and Persian (Canagarajah, 2002), language learners prefer to move toward understanding relations of power and dominant discourse, how to access it and how to create new meanings in the writing. In the iterative cycle of action research, participants work collaboratively with the researchers to improve their understanding of critical issues of writing. Furthermore, participants gained insight by actively participating in classroom discussions and working with each other and with the classroom teacher. Results of reflective interview, teacher observation notes and self-evaluated questionnaire revealed that when engaging in an action research project, participants' awareness of the act of writing reconstructed and their assumptions about the rhetorical patterns of their L1 and L2 were modified.

As regards with the effect of CCR instruction on participants' product, the results of analysis of essays written by participants affirmed the findings obtained from other tools of data collection procedures. Despite overall similarity between participants' L1 and L2 writing before the instruction, the analysis of students' L1/L2 texts after the instruction showed that participants' favored to write English and Persian differently in terms of content and organizational patterns.

At last, but not least, acquiring a "personal practical knowledge" (Golombek, 2009) can be regarded as the ultimate goal of each action research cycle. In collaboration with the language learners, the teacher researchers themselves went through a process of give and take of knowledge and ideas in the course of teaching in order to "create deeper meanings about teaching practices" (Burn, 2010, p. 142).

\subsection{Conclusion, Suggestions and Implications}

The present study shows how action research provides opportunities for language learners improve their critical understanding of the process of writing text in English and Persian. Also the study attempted to change L2 writers' attitude and perception toward the underlying principles of critical contrastive rhetoric by giving them insights about the cultural and rhetorical differences between the two languages, on the one hand, and helping them negotiate their subjectivities in L1 and L2. The effect of this instruction was clearly reflected in the participants' product, i.e. their essay writing prompts at the end of project. This last point can be regarded as one of the indicative of students' improvement in writing. Continued valid and rigorous research is needed, however, to more study L2 writers' problems and difficulties in this area.

On the other end of the continuum of any action research project, the classroom teachers, considered as a contributory factor in "improving the quality of ... learning in a state-maintained education system" (Somekh, 2010, p. 1), should be aware of the potentials of CCR instruction. The following suggestion opens up a new ways for future and further investigations: although the findings indicate that language learners changed their previous and primitive attitudes toward L2 writing, more research is needed to explore the change of perceptions of language teachers in this regard. Language instructors play a pivotal role in giving EFL learners opportunities and insights about the relations of power and language in classroom settings.

The most important implications of this study are the understanding of how Iranian EFL learners perceive the nature of English writing. Using the action research cycles in data collection procedure, the findings have contributed immensely on a group of EFL learners to enhance their understanding of the English and Persian rhetorical distinctions, i.e. raising their critical understanding of contrastive rhetoric between these two languages. The results have implications for language teachers as well. As mentioned above, critical understanding of linguistic differences has received focal attentions in the field of second language writing. The findings of this study can provide a springboard for the practitioners and language teachers in Iran so long as they depict an image of Iranian EFL perception of rhetorical differences between English and Persian.

\section{References}

Allen, L. (2004). Implementing a cultural portfolio project within a constructivist paradigm. Foreign Language Annals, 37 (2), 232-239. http://dx.doi.org/10.1111/j.1944-9720.2004.tb02196.x 
Rafiee, M., Vahid Dastjerdi, H., \& Tavakoli, M.

Bateman, B. (2004). Achieving affective and behavioral outcomes in cultural learning: The case for ethnographic interviews. Foreign Language Annals, 37(2), 240-253. http://dx.doi.org/10.1111/j.1944-9720.2004.tb02197.x

Burn, A. (2010). Doing action research in English language teaching: A guide for practitioners. New York: Routledge.

Canagarajah, S. (2002). Multilingual writers and the academic community: Towards a critical relationship. Journal of English for Academic Purposes, 1, 29-44. http://dx.doi.org/10.1016/S1475-1585(02)00007-3

Carr, W., \& Kemmis, S. (1983). Becoming Critical: knowing through action research. Victoria: Deakin University Press (Republished by Falmer Press (1986) as Becoming Critical: Education, Knowledge and Action Research.).

Conner, U. (1996). Contrastive rhetoric: Cross-cultural aspects of second language writing. Cambridge: Cambridge University Press. http://dx.doi.org/10.1017/CBO9781139524599

Connor, U. (2003). Changing currents in contrastive rhetoric: Implications for teaching and research. In B. Kroll, Exploring the dynamics of second language writing (pp. 218-242). Cambridge: Cambridge University Press. http://dx.doi.org/10.1017/CBO9781139524810.015

Connor, U. (2002). New directions in contrastive rhetoric. TESOL Quarterly, 36, 493-510. http://dx.doi.org/10.2307/3588238

Crismore, A., \& Abdollehzadeh, E. (2011). A review of recent metadiscourse studies: The Iranian context. Nordic Journal of English, 195-220.

Glaser, B. G., \& Strauss, A. L. (1967). The discovery of grounded theory: Strategies for qualitative research. Chicago: Aldine Publishing Company.

Goatly, A. (2000). Critical reading and writing: An introductory coursebook. London: Routledge.

Golombek, P. (2009). Personal practical knowledge in L2 teacher education. In A. Burn, \& J. C. Richards (Eds.), The Cambridge guide to second language teacher education (pp. 157-164). New York: Cambridge University Press.

Hamp-Lyons, L. (1990). Second language writing: Assessment issues. In B. Kroll (Ed.), Second language writing: Research insights for the classroom (pp. 69-87). New York: Cambridge University Press. http://dx.doi.org/10.1017/CBO9781139524551.009

Janks, H. (2000). Domination, access, diversity and design: A synthesis for critical literacy education. Educational Review, 52(2), 175-186. http://dx.doi.org/10.1080/713664035

Kaplan, R. (1996). Cultural thought patterns in intercultural education. Language Learning, 16, 1-20. http://dx.doi.org/10.1111/j.1467-1770.1966.tb00804.x

Kaur, S. (2013). Critical literacy practices of English major in a tertiary institution. GEMA Online Journal of Language Studies, 13(2), 21-39.

Kubota, R., \& Lehner, A. (2004). Toward critical contrastive rhetoric. Journal of Second Language Writing, 13, 7-27. http://dx.doi.org/10.1016/j.jslw.2004.04.003

Kubota, R. (1998). An Investigation of L1-L2 Transfer in writing among Japanese university students: Implications for contrastive rhetoric. Journal of Second Language Writing, 7(1), 69-100. http://dx.doi.org/10.1016/S1060-3743(98)90006-6

Mackey, A., \& Gass, S. M. (2005). Second language research: Methodology and design. Mahwa, New Jersey: Lawlence Erlbaum Associates Publishers.

McIntyre, A. (2008). Participatory action research. Los Angeles: Sage Publication.

Pennycock, A. (2001). Critical applied linguistics: A critical introduction. Sydney: Lawrence Erlbaum Associates, Inc.

Pishghadam, R., \& Attaran, A. (2013). Rhetorical patterns of argumentation in EFL journals of Persian and English. International Journal of Research Studies in Language Learning, 2(1), 81-90. http://dx.doi.org/10.5861/ijrsll.2012.132

Shor, I. (1999). “What is critical literacy?” Journal of Pedagogy, Pluralism \& Practice. Cambridge, Massachusetts: Lesley College.

Somekh, B. (2006). Action research: A methodology for change and development. New York: Open University 
Press.

Subrahmanian, K. (1975). The need for a contrastive analysis of the cultures of the source and target languages. RELC Journal, 6(2), 1-8. http://dx.doi.org/10.1177/003368827500600201

Tomal, D. R. (2010). Action research for educators. London: Rowman \& Littlefield Education.

Wardekker, W. (1997). Critical pedagogy: An evaluation and a direction for reformulation. Malden: Blackwell Publishers.

Wardekker, W. L., \& Miedema, S. (1997). Critical pedagogy: An evaluation and a direction for reformulation. Curriculum Inquiry, 27(1), 45-61. http://dx.doi.org/10.1111/0362-6784.00036

Willinsky, J. (2007). Of critical theory and critical literacy. Stanford: Stanford University Press.

Yoon, C. (2008). Transfer of rhetorical organization? A within-subject exploration of Korean students' argumentative essays in Korean and English. Unpublished MA scholarly paper, University of Hawai' $\mathrm{i}$ at Mānoa, Honolulu.

Zamel, V. (1997). Toward a model of transculturation. TESOL Quarterly, 340-352.

Appendix A: Bio-data questionnaire

1) Name

$$
\text { Age }
$$

Educational level

2) When did you start learning English? From.......

3) Have you studied English in institutes? Yes .......... No ..........

If yes, how long?

4) I have learned how to write essays in English. Yes No

5) I have learned how to write essays in Persian. Yes No

Appendix B: Questionnaire for students

Please answer the following questions as completely and honestly as possible. Your responses to these questions will not affect your grade on the interview project.

(1) Sex: Male $\square \quad$ Female $\square$

(2) Please rate the following from "strongly disagree" to "strongly agree":

1 = Strongly disagree, 2 = Disagree, 3 = Moderate, 4 = Agree, 5 = Strongly agree

I gained insight into a particular aspect of English language writing. $\quad 12345$

I gained insight into the same aspect in my own first language writing. $\quad 12345$

I became more aware of my own process of language writing.

I engaged in critical thinking during my writing.

I became familiar with resources I might use for future L1/L2 writing. $\quad 12345$

Language is a powerful means of maintaining relations of domination $\quad 12345$

This course gave me the power to access the dominant forms of language. 12345

The course gave me insight into the various types of rhetorical patterns of L1 and L2 12345

I have the ability to generate and reconstruct a number of new meanings in my act of writing. 12345

(3) How much did the project improve your understanding of English/Persian language writing?

Not at all 12345 Very much

(4) With respect to the present writing tasks, did you consciously try to write your English and Persian essays differently in terms of content and/or text organization?

Yes__ No_ If yes, why? 
Appendix C: Location of main idea(s): Argumentative/Persuasive (adapted from Kubota, 1998, pp. 98-99)

1. Initial: The writer's opinion on learning English abroad is stated in the introduction.

2. Middle: The writer's opinion on learning English abroad is stated in the middle section.

3. Final: The writer's opinion on learning English abroad is stated in the conclusion.

4. Collection: There is no encompassing statement of the writer's opinion on learning

English abroad, but the opinion is expressed in more than one location.

5. Obscure: The writer's opinion on learning English abroad is not clearly stated.

Appendix D: Macro-level patterns: Argumentative/Persuasive (from Kubota, 1998, p.100)

1. Col: Equally weighted arguments on the topic are juxtaposed.

2. Comp: Two elements are stated in a relationship of compare/contrast, adversative or alternative.

\section{Explanation}

Exp: The writer's opinion on the topic is presented and then a supporting reason is stated.

$\operatorname{Exp}(\mathrm{Col})$ : The writer's opinion on the topic is presented and then supporting reasons are enumerated.

$\operatorname{Exp}(\mathrm{Comp})$ : The writer's opinion on the topic is presented and then a supporting reason is presented by comparing or contrasting two elements.

\section{Specification}

Spec: The writer's opinion and a preview statement of a supporting reason or a point of view for the subsequent argument are presented, and then it is explained in more detail.

Spec(Co1): The writer's opinion and a preview statement of supporting reasons or a point of view for the subsequent arguments are presented, and then the reasons or arguments are explained in more detail by enumeration.

Spec(Comp): The writer's opinion and a preview statement of supporting reasons or a point of view for the subsequent arguments are presented, and then the reasons or arguments are explained in more detail by comparing/contrasting two elements.

5. Comp $\rightarrow$ Exp: After an opinion, which is against the writer's, is presented, the writer's opinion is stated and it is supported by a reason.

6. Induction (Ind): The main idea is placed at the end and preceding arguments constitute supporting reason(s) for it.

Ind (Co1): The writer's opinion is realized in the final section; the preceding arguments constitute premises or reasons which are arranged in a form of enumeration.

Comp $\rightarrow$ Ind: After two elements are stated in a relationship of compare/contrast, adversative or alternative, the writer's opinion is drawn at the end.

7. Other: None of the above. 